九州大学学術情報リポジトリ

Kyushu University Institutional Repository

\title{
Genetically engineered angiogenic cell sheets using magnetic force-based gene delivery and tissue fabrication techniques
}

Aki yama, Hirokazu

Department of Chemical Engineering, Faculty of Engineering, Kyushu University

Ito, Akira

Department of Chemical Engineering, Faculty of Engineering, Kyushu University

Kawabe, Yoshinori

Department of Chemical Engineering, Faculty of Engineering, Kyushu University

Kamihira, Masamichi

Department of Chemical Engineering, Faculty of Engineering, Kyushu University

http://hdl. hand le. net/2324/26626

出版情報：Biomaterials. 31 (6)，pp. 1251-1259，2010-02-01. Elsevier

バージョン:

権利関係: (C) 2009 Elsevier Ltd. 
Genetically engineered angiogenic cell sheets using magnetic force-based gene delivery and tissue fabrication techniques

Hirokazu Akiyama, Akira Ito, Yoshinori Kawabe, Masamichi Kamihira*

Department of Chemical Engineering, Faculty of Engineering, Kyushu University, 744 Motooka, Nishi-ku, Fukuoka 819-0395, Japan

*Corresponding author. Tel.: +81 92802 2743; fax: +81 928022793 .

E-mail address: kamihira@chem-eng.kyushu-u.ac.jp (M. Kamihira). 


\section{ABSTRACT}

A major limitation in tissue engineering is the insufficient formation of blood vessels in implanted tissues, resulting in reduced cell density and graft size. We report here the fabrication of angiogenic cell sheets using a combination of two magnetic force-based techniques which use magnetite cationic liposomes (MCLs), magnetofection and magnetic cell accumulation. A retroviral vector encoding an expression cassette of vascular endothelial growth factor (VEGF) was labeled with MCLs, to magnetically attract the particles onto a monolayer of mouse myoblast $\mathrm{C} 2 \mathrm{C} 12$ cells, for gene delivery. MCL-mediated infection increased transduction efficiency by 6.7-fold compared with the conventional method. During the fabrication of the tissue constructs, MCL-labeled cells were accumulated in the presence of a magnetic field to promote the spontaneous formation of a multilayered cell sheet. VEGF gene-engineered C2C12 (C2C12/VEGF) cell sheets, constructed using both magnetic force-based techniques, were subcutaneously transplanted into nude mice. Histological analyses revealed that on day 14 the C2C12/VEGF cell sheet grafts had produced thick tissues, with a high cell density, and promoted vascularization. This suggests that the method described here represents a powerful strategy in tissue engineering.

Keywords: Magnetite cationic liposome, VEGF, Magnetofection, Cell sheet, Vascularization, Tissue engineering 


\section{Introduction}

Angiogenesis is the vascular sprouting from pre-existing blood vessels into an avascular tissue in the response to various growth factor stimuli [1]. To date, several angiogenesis-related growth factors, such as vascular endothelial growth factor (VEGF), fibroblast growth factor (FGF), platelet-derived growth factor (PDGF) and transforming growth factor- $\beta$ (TGF- $\beta$ ), have been identified [2]. Among these, VEGF is widely recognized as an attractive therapeutic target in diseases requiring pro- $[3,4]$ and anti-angiogenic treatments [5], as it is a major regulator of vessel formation, with high specific activity in endothelial cells.

In the field of tissue engineering, the size and thickness of grafts have been limited by an inadequate infiltration of vessels during the initial phase post-implantation $[6,7]$. Insufficient vascularization reduces cell integration in grafts and causes cell death, which leads to nonfunctional tissues with low cell densities. Thus, the development of pro-angiogenic, tissue-engineered constructs is an important focus of current research. Although there have been extensive examinations into the incorporation of recombinant VEGF protein into scaffolds [8, 9], their efficacy was limited by the short half life of the protein in vivo. Therefore, the genetic modification of implants, using a highly efficient gene delivery method, could achieve the active induction of angiogenesis in the graft.

Magnetic nanoparticles have attracted great attention in various fields of biomedical research [10-13] as two of their major properties are; a responsiveness to magnetic fields and a large surface area for biochemical modification. Magnetite cationic liposomes (MCLs), used for the magnetic labeling of cells with magnetic particles, have been previously developed by encapsulating $10 \mathrm{~nm}$-magnetite nanoparticles in cationic liposomes which creates an electrostatic interaction with the negatively-charged cell 
membrane [14]. We have developed a technique, designated "magnetic force-based tissue engineering (Mag-TE)”, which applies the use of MCLs in tissue engineering to promote the assembly of three-dimensional tissues, in a high-cell density sheet-like structure [15]. This is achieved by accumulating MCL-labeled cells in the presence of a magnetic field. It has been previously shown that magnetofection, a gene delivery technique using magnetic particles, enhances transduction efficiency compared with pre-existing viral and non-viral techniques [16-18]. In a previous study, we demonstrated that retroviral vector particles could be captured using MCLs and concentrated by a magnetic force. We also showed that spatial patterns of reporter gene expression could be created by manipulating MCL-labeled retroviral particles, using magnetic concentrators with micro-scale patterns [19]. Although these results suggest that magnetofection using MCLs is an effective method of fabricating genetically engineered tissue constructs, a feasibility study using a gene of interest for its application has currently not been performed.

In the present study, we examined the feasibility of this strategy to fabricate VEGF gene-engineered myoblast cell sheets possessing angiogenic potential, by using MCL-mediated retroviral gene transduction and tissue fabrication. Transplantation of myoblast-based tissue-engineered constructs holds promise for regeneration of skeletal muscle tissues following traumatic injury or aggressive tumor ablation that often results in significant loss of muscle tissues [20]. Functional skeletal muscles have to integrate abundant blood vessels. Therefore, the angiogenic potential of the VEGF gene-engineered myoblast cell sheets fabricated by Mag-TE technique was evaluated in a subcutaneous transplantation model.

\section{Materials and Methods}




\subsection{Cells and culture}

Mouse C2C12 myoblast cells were cultured in low-glucose Dulbecco’s modified Eagle medium (DMEM; Sigma-Aldrich, St. Louis, MO, USA) supplemented with $10 \%$ fetal bovine serum (FBS; Biowest, Nuaille, France), $0.1 \mathrm{mg} / \mathrm{ml}$ streptomycin sulfate and 100 U/ml potassium penicillin G (Wako Pure Chemical Industries, Osaka, Japan) [21]. Human umbilical vein endothelial cells (HUVECs) (Kurabo, Japan) were cultured in HuMedia-EG2, a commercially available growth medium (Kurabo, Osaka, Japan). Virus-producer 293FT cells were grown in high-glucose DMEM (Sigma-Aldrich) supplemented with 10\% FBS, 0.1mM MEM non-essential amino acids and $10 \mathrm{mM}$ 2-[4-(2-Hydroxyethyl)-1-piperazinyl] ethanesulfonic acid (HEPES; Dojindo laboratories, Kumamoto, Japan). These cells were cultured at $37^{\circ} \mathrm{C}$ in a $5 \% \mathrm{CO}_{2}$ incubator.

\subsection{Cloning of mouse VEGF and vector construction}

Total RNA was extracted from C2C12 cells using a kit (QuickPrep Total RNA Extraction Kit; GE Healthcare, Buckinghamshire, UK) according to the manufacture's protocol. Isolated RNA was reverse-transcribed with ReverTra Ace reverse transcriptase (Toyobo, Osaka, Japan). A DNA fragment of mouse VEGF isoform 164 (mVEGF $\left.{ }_{164}\right)$ was amplified by PCR using the following primers: 5’

CGGGATCCACCATGAACTTTCTGCTGTCTTGGGT 3’ (forward) and 5’ CGGGATCCGAATTCACCGCCTCGGCT 3’ (reverse), which append BamHI sites. PCR was initiated using KOD-plus DNA polymerase (Toyobo, Japan) at $94^{\circ} \mathrm{C}$ for 2 min, followed by 35 cycles of amplification at $94^{\circ} \mathrm{C}$ for $15 \mathrm{~s}, 56^{\circ} \mathrm{C}$ for $30 \mathrm{~s}$ and $68^{\circ} \mathrm{C}$ for $40 \mathrm{~s}$. The retroviral vector plasmid for VEGF expression 
(pQMSCV/CMV-VEGF-IRES-EGFP) was constructed by ligation of the mVEGF 164 DNA fragment into BamHI-digested pQMSCV/CMVHBD-3-IRES-EGFP plasmid [22]. In this vector, VEGF and green fluorescent protein (GFP) are bicistronically expressed under the control of a CMV promoter. The self-ligated pQMSCV/CMV-IRES-EGFP plasmid without VEGF gene was used for production of the control retroviral vector.

\subsection{Retroviral vector production}

Retroviral vector particles were produced by transient transfection with three plasmid DNAs; the retroviral vector plasmid, pcDNA4-gag/pol and pLP/VSV-G [23]. 293FT cells $\left(1.2-1.6 \times 10^{5}\right.$ cells/dish) were seeded onto 60 -mm collagen-coated dishes (Asahi Techno Glass, Tokyo, Japan) and cultured to 90\% confluency. Cells were then co-transfected by lipofection using $20 \mu \mathrm{l}$ of lipofectamine2000 (Invitrogen, Carlsbad, CA, USA) and the three plasmids (3.07 $\mu \mathrm{g}$ retroviral vector plasmid, $3.07 \mu \mathrm{g}$ pcDNA4-gag/pol and $1.86 \mu g$ pLP/VSV-G). At $48 \mathrm{~h}$ post-transfection, the viral particle-containing medium was collected and filtered to remove cell debris using a 0.45 $\mu \mathrm{m}$-cellulose acetate filter (Advantec, Tokyo, Japan).

\subsection{Preparation of MCLs}

The magnetite $\left(\mathrm{Fe}_{3} \mathrm{O}_{4}\right.$; average particle size, $\left.10 \mathrm{~nm}\right)$ used as the core of MCLs was supplied from Toda Kogyo (Hiroshima, Japan). Cationic liposomes of MCLs, composed of $N$-( $\alpha$-trimethylammonioacetyl)-didodecyl-D-glutamate chloride (TMAG), dilauroylphosphatidyl-choline (DLPC) and dioleoylphosphatidyl-ethanolamine (DOPE) in a molecular ratio of 1:2:2, were prepared as described previously [14]. Briefly, the lipid mixture was dissolved in chloroform and evaporated to form lipid films. The films were then hydrated in colloidal magnetites under vortexing to form liposomes, followed 
by sonication for $30 \mathrm{~min}$.

\subsection{Retroviral magnetofection using MCLs}

C2C12 cells $\left(3 \times 10^{3}\right.$ cells/well) were seeded into the wells of 96 well-plates (Greiner Bio-One, Frickenhausen, Germany) 1 day prior to infection. To investigate the effect of MCL concentration on transduction efficiency, the viral solution (150 $\mu \mathrm{l})$ was mixed with various amount of MCLs (0, 75, 150, 300 or 600 ng-magnetite). The magnetite concentrations at infection corresponded to $0,12.5$, 25, 50 or 100 pg per cell in the culture wells. After incubating for $30 \mathrm{~min}$ on ice, the solutions containing the MCL-retroviral particle complexes were added to the cell-cultured wells and a 96-magnet plate (Oz Biosciences, Marseille, France) was placed under the well plates to attract the complexes to the cells. After 6-h incubation at $37^{\circ} \mathrm{C}$, the viral-containing medium was exchanged for growth medium and the magnet was removed. In some experimental conditions, polybrene was added to viral solution at the concentration of 8 $\mu \mathrm{g} / \mathrm{ml}$.

To examine the effect of the magnetic force intensity on transduction efficiency, neodymium and ferrite magnets (diameter, $50 \mathrm{~mm}$; height, $10 \mathrm{~mm}$ ) were employed for magnetofection using MCLs (600 ng-magnetite). The magnetic flux densities were measured at the culture surfaces using a gauss meter (F. W. Bell, Orlando, FL, USA) and corresponded to 1010G (96-magnet plate), 617G (neodymium magnet) and 278G (ferrite magnet).

To determine the viral titration, C2C12 cells were infected using a tenfold serial dilution of the viral solution and GFP-expressing C2C12 cells were counted under a fluorescent microscope (Olympus, Tokyo, Japan) $48 \mathrm{~h}$ post-infection. All of the retroviral infections were in the range of $0.46-5.7 \times 10^{6} \mathrm{IU} / \mathrm{ml}$ viral titers, determined in 
the presence of polybrene.

\subsection{Fabrication of VEGF gene-engineered cell sheets by Mag-TE}

C2C12 cells $\left(1 \times 10^{5}\right.$ cells/dish) were seeded into a 35-mm tissue culture dish (Greiner Bio-One). After 24-h culture, 2 ml MCL-retroviral particle complex solution (20 $\mu$ g-magnetite) was added to the cell-culture dish and a cylindrical neodymium magnet was placed under the dish. The magnetite concentration corresponded to $100 \mathrm{pg}$ per cell. At 6 h post-infection, the virus-containing medium was exchanged for growth medium. After 1-d culture, MCLs were added to the cells (100 pg/cell) and the cells were cultured for $4 \mathrm{~h}$. Subsequently, the cells were harvested and $500 \mu \mathrm{l}$ of medium containing $1.2 \times 10^{6}$ cells was seeded inside a silicone rubber tube (inner diameter, 1 $\mathrm{cm}$ ), which was placed at the center of a $35 \mathrm{~mm}$ culture dish (hydrophobic lumox dish, Cat. no. 9607-7331, Greiner Bio-One). Immediately thereafter, a cylindrical neodymium magnet (diameter, $30 \mathrm{~mm}$; height, $15 \mathrm{~mm}$ ) was placed under the dish to accumulate MCL-labeled cells on the culture surface and form a multilayered cell sheet. After 2-h culture, the silicone tube was removed and medium $(1.5 \mathrm{ml})$ was added, followed by continued cultivation.

Cell sheets were observed using a fluorescence microscope (BZ-9000; Keyence, Osaka, Japan), to confirm GFP expression, and the images were processed by BZ-Analyzer (Keyence).

\subsection{Detection of VEGF expression}

Cell sheets and culture media were collected $24 \mathrm{~h}$ after the construction of cell sheets to determine VEGF expression.

Total RNA was extracted from the cell sheets for semi-quantitative RT-PCR, and 
reverse-transcribed to prepare cDNAs, as described previously herein. Using the cDNA samples, specific sequences were amplified by PCR using the following primers: mVEGF $_{164}$ (forward, 5’ ACAGAACAAAGCCAGAAAATCACTG 3'; reverse, 5’ GTTTAACTCAAGCTGCCTCGCC 3’) and mGAPDH (forward, 5’ CTACCCCCAATGTGTCCGTC 3’; reverse, 5’ GCTGTTGAAGTCGCAGGAGAC 3’). PCR was initiated using G-Taq DNA polymerase (Cosmo Genetech, Seoul, Korea) at $94^{\circ} \mathrm{C}$ for $2 \mathrm{~min}$, followed by $20-30$ cycles of amplification at $94^{\circ} \mathrm{C}$ for $15 \mathrm{~s}, 56^{\circ} \mathrm{C}$ for 30 $\mathrm{s}$ and $72^{\circ} \mathrm{C}$ for $9 \mathrm{~s}$. The PCR products were electrophoresed on a 3\% agarose gel and stained with ethidium bromide for observation.

To detect VEGF secretion from the cell sheet, the culture medium was analyzed by Western blotting. The media (10 $\mu \mathrm{l})$ were mixed with SDS-PAGE sample buffer containing 2-mercaptoethanol and boiled for $5 \mathrm{~min}$. Subsequently, the samples were electrophoresed using $12 \%$ acrylamide gels and fractionated proteins were transferred to a polyvinylidene-fluoride membrane at $0.35 \mathrm{~A}$ for $90 \mathrm{~min}$. The membrane was then immersed with blocking solution, composed of 5\% skimmed milk in Tris-buffered saline containing $0.05 \%$ Tween 20 (TBS-T), at $4^{\circ} \mathrm{C}$ overnight. Following this, the membrane was incubated with polyclonal anti-VEGF antibody (Santa Cruz Biotechnology, Santa Cruz, CA, USA), diluted 1:200 in blocking solution, at room temperature for $1 \mathrm{~h}$, followed by further incubation with horseradish peroxidase (HRP)-conjugated anti-rabbit IgG antibody (Santa Cruz Biotechnology) diluted 1:5000 using the same reaction condition. The membrane was washed with TBS-T after each step. The HRP activity was detected using a kit based on chemiluminescence (ECL detection system; GE Healthcare)

To quantify VEGF secretion in the medium, the samples were analyzed using a kit based on enzyme-linked immunosorbent assay (mouse VEGF ELISA kit; Ray Biotech, 
Norcross, GA, USA), in accordance with the manufacturers protocol.

\subsection{In vitro bioassay of VEGF secreted from cell sheets}

The effect of VEGF activity on proliferation and tube formation of endothelial cells was measured in C2C12 cells by a slight modification of previously reported protocols [24]. During the proliferation assay, HUVECs were seeded into wells of a 96-well plate at a density of $2 \times 10^{3}$ cells/well and cultured with growth medium for $24 \mathrm{~h}$. The cells were then carefully rinsed twice with phosphate buffered saline (PBS) and exposed for $6 \mathrm{~h}$ to Humedia-EB2 supplemented with 2\% FBS (basal medium). Subsequently, the medium was exchanged for basal medium containing 100 ng/ml mVEGF m64 $_{\text {(Relia Tech }}$ GmbH, Braunschweig, Germany), 3\% myoblast growth medium or 3\% conditioned medium collected from the cell sheet cultures. After $96 \mathrm{~h}$ of stimulation, $10 \mu \mathrm{l}$ WST-8 solution (Cell Counting Kit 8; Dojindo Laboratories) was added to each well and incubated for $4 \mathrm{~h}$, and the absorbance at $405 \mathrm{~nm}$ was measured using a spectrophotometer (Smart Spec3000; Bio-Rad Laboratories, Hercules, CA, USA).

In the tube formation assay, $250 \mu \mathrm{l}$ growth factor-reduced Matrigel (BD Biosciences, Franklin Lakes, NJ, USA) was added to each well of a 24-well plate (Greiner Bio-One) and allowed to polymerize for $30 \mathrm{~min}$ at $37^{\circ} \mathrm{C}$. HUVECs were pre-stained with CMTMR (5-(and-6)-(((4-chloromethyl)benzoyl)amino)tetramethylrhodamine; orange fluorescent probe) and the cells ( $5 \times 10^{4}$ cells/well) were seeded onto the gel with conditioned medium $(500 \mu \mathrm{l})$. After $12 \mathrm{~h}$ of stimulation, three random fields in each well were photographed under the fluorescent microscope (Olympus). To compare the tubular length, tubes in the images were manually traced with lines and the number of pixels occupied by the lines was calculated using image analysis software (Adobe Photoshop 6.0; Adobe Systems, San Jose, CA, USA). 


\subsection{Subcutaneous transplantation of cell sheets}

Female 4- to 5-week old KSN/Slc (Japan SLC, Shizuoka, Japan) nude mice were used for transplantation experiments. Mice were anesthetized by intraperitoneal injection of pentobarbital and a small incision was created in the dorsal skin. Cell sheets, constructed by 1-d cultivation using a magnet, were rinsed twice with PBS and harvested on thin films as a physical support. Subsequently, the cell sheet and film was inserted subcutaneously into the dorsal skin through the incision and the film was removed, leaving the cell sheet on the underlying tissue. Thereafter, incisions were closed using silk sutures. At 14 days post-implantation, mice were sacrificed and the grafts were resected.

All animal experiments in this study were approved by the Ethics Committee for Animal Experiments of the Faculty of Engineering, Kyushu University (A19-114-1).

\subsection{Histological examination}

Resected grafts were fixed in $4 \%$ formaldehyde solution and embedded in paraffin. Thin slices $(4 \mu \mathrm{m})$ were placed on silanized slides for immunohistochemistry or staining with hematoxylin-eosin (H\&E). For immunofluorescent staining of CD31, anti-mouse CD31 antibody (Santa Cruz Biotechnology) and Alexa Fluor 488-conjugated anti-goat antibody (Invitrogen) were used as primary and secondary antibodies, respectively. Briefly, sections were blocked with $1 \%$ bovine serum albumin for 10 min at $37^{\circ} \mathrm{C}$, followed by overnight incubation at $4^{\circ} \mathrm{C}$ with the primary antibody and 30 min at $37^{\circ} \mathrm{C}$ with the secondary antibody. After each step slides were washed with TBS. To quantify the microvessel areas, eight non-overlapping fields in each section of the graft were photographed under the fluorescent microscope. The number of pixels occupied by 
CD31-positive vessels was divided by the total pixels within the image to calculate the microvessel area percentage using image analysis software (Adobe Photoshop 6.0). To evaluate tissue formation, the cross-sectional area in each graft was measured using H\&E-stained sections by a similar procedure as described above. The number of nuclei was counted to calculate cell density of the grafts.

\subsection{Statistical analysis}

All data are expressed as means \pm SD. Statistical comparisons were evaluated using one-way analysis of variance (ANOVA), and any values of $p<0.05$ were considered significantly different.

\section{Results}

\subsection{Retroviral magnetofection using MCLs}

The retroviral magnetofection procedure using MCLs is illustrated in Fig. 1a. Retroviral vectors were captured by MCLs via electrostatic interaction, as reported previously [19], and the MCL-retroviral particle complexes were attracted onto a monolayer of C2C12 cells through the application of a vertical magnetic force. To optimize the magnetofection condition, the effects of magnetite concentration and magnetic force intensity on the viral infectivity were examined. First, the magnetofection experiment was performed by varying MCL amounts, with 0-600 ng-magnetite in $150 \mu \mathrm{l}$ viral solution, under a fixed magnetic field intensity (Fig. 1b). The magnetite concentrations corresponded to 0-100 pg per cell in the culture wells. We have previously confirmed that the addition of MCLs in this range did not affect the viability of C2C12 cells [25]. Transduction efficiency was measured for each MCL 
amount when the efficiency without MCLs was expressed as 1.0. As shown in Fig. 1b, the transduction efficiency was dramatically enhanced by increasing magnetite amount in the range of 0-150 ng; however, only a slight improvement was observed above this range (> $150 \mathrm{ng}$ ). This indicates that $>150 \mathrm{ng}$ magnetite is necessary for sufficient conjugation of viral particles with MCLs. Following this, the MCL-mediated magnetofection was performed at a constant MCL amount (150 ng) using three different magnets with magnetic flux densities of 278,617 or $1010 \mathrm{G}$ at the culture surfaces. Figure 1c shows the transduction efficiency for each magnetic flux density when the efficiency without a magnetic field was expressed as 1.0. Transduction efficiency increased with increased magnetic field intensity, indicating that transduction efficiency depends on the magnetic field intensity.

To evaluate the potential of magnetofection using MCLs, the transduction efficiencies were compared for several conditions, including a conventional method using a cationic polymer, polybrene (Fig. 2). Relative transduction efficiencies to that for polybrene alone are shown in Fig. 2b. Unexpectedly, as compared with solely infected cells (without using polybrene and MCLs), there was no increase in transduction efficiency for cells infected using polybrene and/or MCLs in the absence of a magnet. This suggests that the cationic agents had no significant effects on the retroviral infection of C2C12 cells. Conversely, the transduction efficiency was 6.7-fold higher for the magnetofection using MCLs and magnetic force, indicating that magnetofection using MCLs improved retroviral infection by magnetically attracting retroviral vectors onto target cells. This suggests that this method is applicable to gene therapy requiring the high-expression of a target gene.

\subsection{Fabrication and characterization of VEGF gene-engineered cell sheets using MCLs}


A procedure for fabrication of VEGF gene-engineered C2C12 cell (C2C12/VEGF) sheets by MCLs and magnetic force is illustrated in Fig. 3a. After C2C12 cells were transduced with VEGF gene using the magnetofection technique, MCL-labeled C2C12/VEGF cells were three-dimensionally accumulated onto a non-cell adherent surface using a magnetic force. After 1-d culture using a magnet, the cells formed a multilayered sheet-like construct. The resultant cell sheet had a brown color under the bright-field microscope due to the presence of magnetite (Fig. 3b). In the present study, as the transduced cells co-express both VEGF and GFP, the cell sheets expressing GFP were observed under the fluorescent microscope (Figs. 3c, d). In our previous study, C2C12 cell sheets with a similar thickness were prepared using Mag-TE technique, and the histological analysis revealed that there was no substantial necrotic area within the cell sheets at least 1-d after the construction [26]. For the long-term maintenance of cell sheets in vivo, the induction of vessels may be necessary. Additionally, the fluorescent intensity at the border of the cell sheets was appeared to be stronger than that at the center (Fig. 3c). This was not due to the cell necrosis at the center, as mentioned above. As shown in a previous report, cell sheets started to shrink gradually after the fabrication and the border of them rolled inward [15]. Thus, the border of the cell sheet became thicker, resulted in the enhanced fluorescent intensity at the border.

To detect exogenous VEGF gene expression, cell sheets were analyzed by semi-quantitative RT-PCR and Western blotting. Control cell sheets expressing only GFP (C2C12/GFP sheets) were also fabricated using the same procedure. As can be seen in Fig. 3e, a small amount of the endogenous VEGF expression was observed in the C2C12/GFP sheets, which is consistent with a previous report [27]. In contrast, a higher exogenous VEGF expression was observed in the C2C12/VEGF sheets (Fig. 3e). In the Western blot analysis using the anti-VEGF antibody, a single band with a 
molecular weight of approximately $25 \mathrm{kDa}$ was detected for the culture medium from the C2C12/VEGF sheets (Fig. 3f). Conversely, the VEGF secretion was undetectable from the culture of the C2C12/GFP sheets. VEGF secretion into the medium was also measured by ELISA. The secretion levels of C2C12/GFP and C2C12/VEGF sheets were $2.98 \pm 0.04$ and $240 \pm 29 \mathrm{ng} / \mathrm{day}$, respectively. These results demonstrate that the VEGF gene-engineered cell sheets were successfully fabricated by combining the magnetofection and Mag-TE techniques.

\subsection{In vitro bioassay of VEGF secreted from cell sheets}

HUVECs were cultured in the basal medium containing 3\% conditioned medium from each cell sheet culture for $4 \mathrm{~d}$, and the cell proliferation was determined by WST-8 assay (Fig. 4a). No significant difference in cell proliferation was observed among the groups cultured with basal medium alone and the conditioned medium from C2C12/GFP sheets or medium containing myoblast growth medium. In the group using conditioned medium from C2C12/GFP sheets, the rate of proliferation did not change even when HUVECs were cultured with $10 \%$ conditioned medium (data not shown). In contrast, a significantly higher level of HUVEC proliferation was observed for the culture containing conditioned medium from C2C12/VEGF sheets compared with basal medium alone or conditioned medium from C2C12/GFP sheets. The proliferation was almost equivalent to the culture containing a recombinant VEGF protein standard (100 ng/ml). Following this, HUVECs were seeded onto Matrigel and in vitro morphological differentiation into vascular structures was investigated. As shown in Figs. 4b and c, HUVECs cultured with conditioned medium from C2C12/VEGF sheets formed well-organized networks compared with the control groups, and the tube length was more than 1.5-fold compared with that cultured in basal medium. Overall, the results in 
the tubular formation assay supported the cell proliferation assay (Fig. 4a, b), suggesting that VEGF secreted from C2C12/VEGF sheets is biologically active. Although VEGF was detected in the medium from C2C12/GFP sheets by ELISA, the biological activities for both assays was negligible due to the extremely low level of VEGF expression.

\subsection{Transplantation of VEGF gene-engineered cell sheet}

To evaluate the angiogenic potential of VEGF gene-engineered cell sheets in vivo, C2C12/VEGF sheets were transplanted into subcutaneous spaces of nude mice. At 2 weeks post-transplantation, the grafts were retrieved and subjected to histological examinations. The representative sectional images of immunofluorescent staining for CD31 within the grafts are shown in Fig. 5a. Capillary vessels with a remarkably high density were observed in C2C12/VEGF sheet-derived tissues (Fig. 5a). The percentage of microvessel area within the tissues of C2C12/VEGF sheets was significantly higher than that of C2C12/GFP sheets (Fig. 5b). This high vascularity was also confirmed by macroscopic observation during the retrieval of grafts (data not shown).

Figure 5c shows the representative micrographs of H\&E-stained sections of transplants. Both grafts formed cell-dense tissues containing brown magnetite nanoparticles. The cell densities for C2C12/GFP and C2C12/VEGF sheet-derived tissues were $9915 \pm 2147$ and $9613 \pm 1112$ cells/mm² -section, respectively, which are not statistically different. However, the size and thickness of the grafts were apparently different. C2C12/VEGF sheet-derived tissues were composed of a core region containing magnetite-labeled C2C12/VEGF cells and a surrounding thick peripheral region formed by cell proliferation. This resulted in the formation of a bulky tissue mass, compared with C2C12/GFP tissues which formed a reduced core and surrounding regions. Multinucleated myotubes were observed in both periphery and core regions of 
C2C12/VEGF sheet-derived tissues (data not shown), indicating that the transplanted myoblasts proliferated and migrated into the peripheral region from the core region. The cross-sectional area of C2C12/VEGF tissues was 2-fold larger than that of C2C12/GFP tissues (Fig. 5d). Taken together, these results suggest that VEGF gene-engineered cell sheets provide sufficient tissue vascularization and promote the growth of grafts while maintaining a high-cell density due to enhanced nutrient supply. Thus, this approach is applicable to repair of skeletal muscle tissue defect.

\section{Discussion}

Genetically engineered angiogenic tissue constructs have a great potential in cell-based therapies. They accelerate the formation of functional tissue through increased vascularization which is induced by recombinant angiogenic growth factors secreted from genetically engineered cells. Herein this study, we applied magnetic biomanipulation techniques for both gene transfer and tissue fabrication processes whose technological developments are considered important for the next-generation of regenerative medicine.

As angiogenesis in response to VEGF stimulation occurred in a dosage dependent manner [28], successful treatment requires the application of high-efficient gene transfer methods. In the present study, we utilized a magnetic gene delivery technique, magnetofection, in which MCL-retroviral vector complexes were attracted onto a monolayer cultured cells using magnetic force. This increased transduction efficiency by 6.7-fold compared with the conventional method using polybrene. In general, cationic polymers, including polybrene, have been widely used for the enhancement of retroviral infection by increasing the flux of active viruses to the cells [29, 30]. However, 
in this study, polybrene addition did not improve the gene transduction in C2C12 cells (Fig. 2), which may be due to a cell type-specific sensitivity. In addition, similar to the results reported by Scherer et al. [17], polybrene addition decreased the efficiency of magnetofection by half using MCLs (Fig. 2). This may be due to the competitive binding between polybrene and MCLs to the retroviral particles. In this study, the transduction efficiency was improved by increasing the magnetic force intensity (Fig. 1c). As MCL-retroviral particle complexes were rapidly attracted to the magnet placed under the culture plate, even when the $278 \mathrm{G}$ ferrite magnet was used, it may be possible to achieve high infection of MCL-mediated magnetofection with C2C12 cells. Several researchers demonstrated that the increases of transduction levels could be induced by using agitating magnetic fields [16, 31], suggesting that the cellular uptake of vector-associated particles was promoted by additional physical energies. Therefore, we speculate that the cellular uptake of magnetite nanoparticles is enhanced by physical energies due to magnetic force.

We have developed a magnetic tissue fabrication technique in which MCL-labeled cells were accumulated three-dimensionally in the presence of magnetic field and cultured to form a multilayered sheet-like structure [15, 25]. In our preliminary experiment, cell suspension of wild-type or VEGF over-expressing C2C12 cells labeled with MCLs was injected subcutaneously into nude mice using a needle. In this case, only a small tissue was formed at the injection site due to insufficient organization of cells, although the enhanced angiogenesis was observed for the injection of VEGF over-expressing cells. In contrast, the cells forming a sheet-like construct were strongly attached each other, maintaining the tissue structure. Kondoh et al. also reported the effectiveness of pre-assembly of cells in myoblast graft implantation [32]. Thus, the transplantation of cell sheets constructed in vitro may be an effective method for 
delivering cells. Moreover, the true benefit of this technology is that cell-dense tissues mimicking normal tissues can be created compared with conventional scaffold-based procedures [33, 34]. Particularly, high-cell density culture, where cell-cell contacts are tightly maintained, enables to develop the skeletal muscle tissue with a substantial function, as shown previously [21]. In the present study, the artificial skeletal muscle tissue was constructed by the magnetic tissue fabricating technique using MCLs. Although the thickness of magnetic tissue-engineered cell sheets is controllable by seeding cell number, grafts with substantial thickness, volume, and cell density are more preferable to achieve higher therapeutic performances by transplantation. However, owing to the cell-dense property, it may cause difficulty in mass transport, which induces necrosis within grafts. We evaluated the angiogenic potential of C2C12/VEGF sheets created by combining magnetofection and magnetic tissue fabrication techniques. Histological analysis revealed that C2C12/VEGF sheet-derived tissue maintained a high-cell density by promoting vascular network formation and produced thick tissues compared with the control grafts (Fig. 5). This indicates that VEGF gene introduction was an effective strategy for the induction of angiogenesis into cell-dense constructs. In contrast, although Shimizu et al. succeeded to create $\sim 1 \mathrm{~mm}$ thick tissue by the step-by-step polysurgery of thin cell sheets with 1-d intervals [35], this procedure may be impractical for the clinical application due to its complexity. Alternatively, several groups have attempted to construct pre-vascularized networks within the artificial tissues and demonstrated the rapid anastomosis in the host vasculature [36, 37]. However, the formation of these networks requires complicated culture conditions and a long-term culture in vitro, which may limit the application. We have proposed here a simple and inexpensive approach with a continuous procedure composed of gene transfer and tissue fabrication processes using the magnetic force-based technique. 
Moreover, it was truly effective in terms of positive induction of angiogenesis, and thus useful for efficient tissue regeneration.

Functionality and maturation of the newly formed blood vessels in the grafts are important issues. We could confirm the presence of blood cells in the vessels formed within C2C12/VEGF sheet-derived tissues (data not shown). In addition, the cells stained with $\alpha$-smooth muscle actin antibodies were detected around the vessels in the peripheral region of the graft, indicating the presence of smooth muscle cells. These results suggest that the VEGF-induced vessels were inosculated with the host's vasculature and functional for metabolic exchange, although they might be insufficient in maturation. Korpisalo et al. demonstrated that combination gene transfer of VEGF and PDGF successfully induced the effective vessel maturation [38], because PDGF mediated pericyte proliferation and migration, and thus associated with vessel maturation. Therefore, the magnetic VEGF gene transfer combined with a supportive angiogenic gene such as PDGF, which enhances vessel stabilization, may improve vessel functions.

There are issues that remain to be investigated or addressed for the clinical application of this approach. In vivo administrations of magnetic particles have been attempted as a contrast agent for magnetic resonance imaging (MRI) [39] and as a heating mediator for cancer hyperthermia [40]. In a previous experiment [41], a high dose of MCLs (90 mg/mouse) was administered intraperitoneally into mice to examine the effect of magnetite exposure in vivo. The magnetite nanoparticles were completely cleared from circulation by 10th day after injection, and none of the 10 mice injected with MCLs died during the study. In the present study, although the amount of MCLs within transplanted cells was a negligible level ( $<0.24 \mathrm{mg} /$ mouse) compared with the previous study, the localized accumulation of magnetite were clearly evident even after 
$14 \mathrm{~d}$ of implantation (Fig. 5c). When C2C12 cells with or without MCL-labeling were injected into the subcutaneous space of nude mice using a needle, the size of tissue constructs formed was similar between with and without MCL-labeling, suggesting that the MCL-labeling did not affect in vivo cell survival and tissue formation. For clinical application, further researches on the effect of MCL-labeling on cell and tissue survival may be necessary. In addition, although retroviral vectors possess several beneficial points in gene therapy, such as stable integration of a target gene into host genome and continuous protein expression at high level, the use of retroviral vectors may trigger oncogenesis by upregulating cellular proto-oncogenes. As the safer gene delivery method, plasmid vectors may be preferable for human applications, although the expression is transient. As MCL-mediated magnetofection was applicable for plasmid vectors [18], the effectiveness for fabrication of angiogenic cell sheets should be compared between the gene vectors.

\section{Conclusions}

In this study, we combined magnetic gene delivery and tissue fabrication techniques to create VEGF gene-engineered myoblast cell sheets. Here, the efficient gene transfer and the induction of cell-dense tissue were successfully achieved. Moreover, VEGF gene-engineered cell sheet grafts produced well-vascularized tissues with substantial mass, thickness and cell density when subcutaneously implanted into nude mice. Thus, this procedure may be applicable not only to the tissue regeneration where the angiogenesis is beneficial but also to the other therapeutic situations in which the useful protein expressions for tissue engineering or gene therapy are required. 


\section{Acknowledgments}

We thank Toda Kogyo Co. for kindly supplying the magnetite. We are also grateful to Mr. Y. Suenaga and Mr. S. Huang for technical assistances. One of the authors, Hirokazu Akiyama, is a research fellow of the Japan Society for the Promotion of Science (JSPS). This work was supported in part by Grants-in-Aid for Scientific Research (nos. 21686079 and 20034043) from JSPS.

\section{References}

[1] Byrne AM, Bouchier-Hayes DJ, Harmey JH. Angiogenic and cell survival functions of vascular endothelial growth factor (VEGF). J Cell Mol Med 2005;9:777-94.

[2] Yancopoulos GD, Davis S, Gale NW, Rudge JS, Wiegand SJ, Holash J. Vascular-specific growth factors and blood vessel formation. Nature 2000;407:242-8.

[3] Kang SW, Lim HW, Seo SW, Jeon O, Lee M, Kim BS. Nanosphere-mediated delivery of vascular endothelial growth factor gene for therapeutic angiogenesis in mouse ischemic limbs. Biomaterials 2008;29:1109-17.

[4] Yockman JW, Choi D, Whitten MG, Chang CW, Kastenmeier A, Erickson H, et al. Polymeric gene delivery of ischemia-inducible VEGF significantly attenuates infarct size and apoptosis following myocardial infarct. Gene Ther 2009;16:127-35.

[5] Korsisaari N, Kasman IM, Forrest WF, Pal N, Bai W, Fuh G, et al. Inhibition of VEGF-A prevents the angiogenic switch and results in increased survival of Apc+/min mice. Proc Natl Acad Sci U S A 2007;104:10625-30.

[6] Rouwkema J, Rivron NC, van Blitterswijk CA. Vascularization in tissue 
engineering. Trends Biotechnol 2008;26:434-41.

[7] Lokmic Z, Mitchell GM. Engineering the microcirculation. Tissue Eng Part B Rev 2008;14:87-103.

[8] Nillesen ST, Geutjes PJ, Wismans R, Schalkwijk J, Daamen WF, van Kuppevelt TH. Increased angiogenesis and blood vessel maturation in acellular collagen-heparin scaffolds containing both FGF2 and VEGF. Biomaterials 2007;28:1123-31.

[9] Freeman I, Cohen S. The influence of the sequential delivery of angiogenic factors from affinity-binding alginate scaffolds on vascularization. Biomaterials 2009;30:2122-31.

[10] Ito A, Shinkai M, Honda H, Kobayashi T. Medical application of functionalized magnetic nanoparticles. J Biosci Bioeng 2005;100:1-11.

[11]Corchero JL, Villaverde A. Biomedical applications of distally controlled magnetic nanoparticles. Trends Biotechnol 2009;27:468-76.

[12] Mannix RJ, Kumar S, Cassiola F, Montoya-Zavala M, Feinstein E, Prentiss M, et al. Nanomagnetic actuation of receptor-mediated signal transduction. Nat Nanotechnol 2008;3:36-40.

[13] Wilhelm C, Bal L, Smirnov P, Galy-Fauroux I, Clément O, Gazeau F, et al. Magnetic control of vascular network formation with magnetically labeled endothelial progenitor cells. Biomaterials 2007;28:3797-806.

[14] Shinkai M, Yanase M, Honda H, Wakabayashi T, Yoshida J, Kobayashi T. Intracellular hyperthermia for cancer using magnetite cationic liposomes: in vitro study. Jpn J Cancer Res 1996;87:1179-83.

[15] Ito A, Hayashida M, Honda H, Hata K, Kagami H, Ueda M, et al. Construction and harvest of multilayered keratinocyte sheets using magnetite nanoparticles and magnetic force. Tissue Eng 2004;10:873-80. 
[16] Dobson J. Gene therapy progress and prospects: magnetic nanoparticle-based gene delivery. Gene Ther 2006;13:283-7.

[17] Scherer F, Anton M, Schillinger U, Henke J, Bergemann C, Krüger A, et al. Magnetofection: enhancing and targeting gene delivery by magnetic force in vitro and in vivo. Gene Ther 2002;9:102-9.

[18] Ino K, Kawasumi T, Ito A, Honda H. Plasmid DNA transfection using magnetite cationic liposomes for construction of multilayered gene-engineered cell sheet. Biotechnol Bioeng 2008;100:168-76.

[19] Ito A, Takahashi T, Kameyama Y, Kawabe Y, Kamihira M. Magnetic concentration of a retroviral vector using magnetite cationic liposomes. Tissue Eng Part C Methods 2009;15:57-64.

[20]Bach AD, Beier JP, Stern-Staeter J, Horch RE. Skeletal muscle tissue engineering. J Cell Mol Med 2004;8:413-22.

[21]Fujita H, Shimizu K, Nagamori E. Novel method for fabrication of skeletal muscle construct from the C2C12 myoblast cell line using serum-free medium AIM-V. Biotechnol Bioeng 2009;103:1034-41.

[22] Ito A, Takahashi T, Kawabe Y, Kamihira M. Human beta defensin-3 engineered keratinocyte sheets constructed by a magnetic force-based tissue engineering technique. J Biosci Bioeng 2009;108:244-7.

[23] Hotta A, Saito Y, Kyogoku K, Kawabe Y, Nishijima K, Kamihira M, et al. Characterization of transient expression system for retroviral vector production. $\mathrm{J}$ Biosci Bioeng 2006;101:361-8.

[24]Zhuge X, Murayama T, Arai H, Yamauchi R, Tanaka M, Shimaoka T, et al. CXCL16 is a novel angiogenic factor for human umbilical vein endothelial cells. Biochem Biophys Res Commun 2005;331:1295-300. 
[25] Akiyama H, Ito A, Kawabe Y, Kamihira M. Fabrication of complex three-dimensional tissue architectures using a magnetic force-based cell patterning technique. Biomed Microdevices 2009;11:713-21.

[26] Yamamoto Y, Ito A, Kato M, Kawabe Y, Shimizu K, Fujita H, et al. Preparation of artificial skeletal muscular tissues by a magnetic force-based tissue engineering technique. J Biosci Bioeng 2009;108:in press.

[27]Bryan BA, Walshe TE, Mitchell DC, Havumaki JS, Saint-Geniez M, Maharaj AS, et al. Coordinated vascular endothelial growth factor expression and signaling during skeletal myogenic differentiation. Mol Biol Cell 2008;19:994-1006.

[28] Davies N, Dobner S, Bezuidenhout D, Schmidt C, Beck M, Zisch AH, et al. The dosage dependence of VEGF stimulation on scaffold neovascularisation. Biomaterials 2008;29:3531-8.

[29]Davis HE, Morgan JR, Yarmush ML. Polybrene increases retrovirus gene transfer efficiency by enhancing receptor-independent virus adsorption on target cell membranes. Biophys Chem 2002;97:159-72.

[30]Davis HE, Rosinski M, Morgan JR, Yarmush ML. Charged polymers modulate retrovirus transduction via membrane charge neutralization and virus aggregation. Biophys J 2004;86:1234-42.

[31]Cai D, Mataraza JM, Qin ZH, Huang Z, Huang J, Chiles TC, et al. Highly efficient molecular delivery into mammalian cells using carbon nanotube spearing. Nat Methods 2005;2:449-54.

[32] Kondoh H, Sawa Y, Miyagawa S, Sakakida-Kitagawa S, Memon IA, Kawaguchi N, et al. Longer preservation of cardiac performance by sheet-shaped myoblast implantation in dilated cardiomyopathic hamsters. Cardiovasc Res 2006;69:466-75. [33]Lu Y, Shansky J, Del Tatto M, Ferland P, Wang X, Vandenburgh H. Recombinant 
vascular endothelial growth factor secreted from tissue-engineered bioartificial muscles promotes localized angiogenesis. Circulation 2001;104:594-9.

[34]De Coppi P, Delo D, Farrugia L, Udompanyanan K, Yoo JJ, Nomi M, et al. Angiogenic gene-modified muscle cells for enhancement of tissue formation. Tissue Eng 2005;11:1034-44.

[35] Shimizu T, Sekine H, Yang J, Isoi Y, Yamato M, Kikuchi A, et al. Polysurgery of cell sheet grafts overcomes diffusion limits to produce thick, vascularized myocardial tissues. FASEB J 2006;20:708-10.

[36]Levenberg S, Rouwkema J, Macdonald M, Garfein ES, Kohane DS, Darland DC, et al. Engineering vascularized skeletal muscle tissue. Nat Biotechnol 2005;23:879-84.

[37]Tremblay PL, Hudon V, Berthod F, Germain L, Auger FA. Inosculation of tissue-engineered capillaries with the host's vasculature in a reconstructed skin transplanted on mice. Am J Transplant 2005;5:1002-10.

[38] Korpisalo P, Karvinen H, Rissanen TT, Kilpijoki J, Marjomäki V, Baluk P, et al. Vascular endothelial growth factor-A and platelet-derived growth factor-B combination gene therapy prolongs angiogenic effects via recruitment of interstitial mononuclear cells and paracrine effects rather than improved pericyte coverage of angiogenic vessels. Circ Res 2008;103:1092-9.

[39]Pike MM, Stoops CN, Langford CP, Akella NS, Nabors LB, Gillespie GY. High-resolution longitudinal assessment of flow and permeability in mouse glioma vasculature: Sequential small molecule and SPIO dynamic contrast agent MRI. Magn Reson Med 2009;61:615-25.

[40] Kawai N, Futakuchi M, Yoshida T, Ito A, Sato S, Naiki T, et al. Effect of heat therapy using magnetic nanoparticles conjugated with cationic liposomes on 
prostate tumor in bone. Prostate 2008;68:784-92.

[41] Ito A, Nakahara Y, Tanaka K, Kuga Y, Honda H, Kobayashi T. Time course of biodistribution and heat generation of magnetite cationic liposomes in mouse model. Jpn J Hyperthermic Oncol 2003;19:151-8. 
Figure captions

Fig. 1. Optimization of retroviral magnetofection using MCLs. a. A schematic presentation of magnetofection procedure. MCLs are added to retroviral vector-containing medium and incubated for 30 min on ice to form MCL-retroviral vector particle complexes. Subsequently, the MCL-treated viral solution is added a monolayer of $\mathrm{C} 2 \mathrm{C} 12$ cells in culture, and a magnet is placed beneath the dish to attract MCL-retroviral vector complexes to the cells. After 48-h incubation, GFP-expressing cells are counted under a fluorescent microscope. b. The effect of MCL concentration on transduction efficiency. Retroviral magnetofection was performed with various magnetite concentrations using a magnet with $1010 \mathrm{G}$ magnetic flux density at the culture surface. The retroviral solution $(150 \mu \mathrm{l})$ was mixed with $\operatorname{MCLs}(0,75,150,300$ or 600 ng-magnetite) and added to the cell-cultured wells in 96-well plates. Data are expressed as fold increase of the group without MCL addition and mean $\pm \operatorname{SD}(n=3) .{ }^{*} P<0.05$ vs. - MCLs group. c. The effect of magnetic force intensity on transduction efficiency. Magnetofection was performed with MCLs (600 ng) in $150 \mu$ r retroviral solution using three types of magnets whose magnetic flux densities at the culture surfaces were 278, 617 and 1010G, respectively. Data are expressed as fold increase of the group without a magnet and mean $\pm \mathrm{SD}(\mathrm{n}=3) .{ }^{*} P<0.05$ vs. - magnetic field group.

Fig. 2. Evaluation of retroviral magnetofection using MCLs. $150 \mu$ viral solutions mixed with or without MCLs (600 ng) and polybrene $(8 \mu \mathrm{g} / \mathrm{ml})$, were added to the cell-cultured wells placed with or without magnets (1010G). After 48-h culture, GFP-expressing cells were counted under a fluorescent microscope. a. Representative fluorescence microscopy images of GFP-expressing C2C12 cells at $48 \mathrm{~h}$ post-infection. The scale bar indicates $200 \mu \mathrm{m}$. b. Relative transduction efficiency to that of conventional method using polybrene (polybrane group). Data are mean \pm SD $(n=3) .{ }^{*} P<0.05$ vs. + polybrene group. ${ }^{\star \star} P<0.05$ vs. polybrene + MCLs + magnet group. 
Fig. 3. Fabrication and characterization of C2C12/ VEGF cell sheets. a. A schematic presentation of fabrication procedure for cell sheets. MCL-labeled C2C12/VEGF cells are seeded inside a silicone rubber tube frame placed in the dish. The cells are attracted and accumulated in 3-D on the bottom of dish by a magnet placed beneath the dish, and then cultured to form a multilayered cell sheet. b, c. The overall view of the C2C12/VEGF cell sheets. Micrographs were taken under the bright-field (b) and fluorescent microscope (c), respectively. $d$. The fluorescence image of cross-section of the C2C12/VEGF cell sheet. e, f. VEGF expression of the cell sheets were analyzed by semi-quantitative RT-PCR (e) and Western blotting (f).

Fig. 4. In vitro bioassay of VEGF secreted by cell sheets. a. Proliferation assay for HUVECs. HUVECs were seeded into 96-well plate and cultured in Humedia-EB2 supplemented with 2\% FBS (basal medium, $\mathrm{BM}$ ) with or without $100 \mathrm{ng} / \mathrm{ml}$ recombinant VEGF protein, 3\% myoblast medium, or conditioned medium (CM) collected from C2C12/VEGF or C2C12/GFP cell sheets. After 96-h culture, cell proliferation was determined by WST-8 assay. Data are mean $\pm \mathrm{SD}(\mathrm{n}=3) .{ }^{\star} P<0.05$ vs. BM group. ${ }^{\star \star} P<0.05$ vs. BM + C2C12/GFP-CM group. b, c. Tubular formation assay for HUVECs. HUVECs were pre-stained with orange fluorescent probe and seeded into the Matrigel-coated 24-well plate, and then cultured with the aforementioned media. After 12-h culture, micrographs were taken under the fluorescent microscope, and the lengths of the tubes in the images were measured (b). Data are expressed as relative tubular length to that of BM group and mean $\pm \mathrm{SD}(\mathrm{n}=3) .{ }^{*} P<0.05$ vs. BM group. ${ }^{*} P<0.05$ vs. BM + C2C12/GFP-CM group. Representative images of morphological features of HUVECs were shown in (c). The scale bar indicates $500 \mu \mathrm{m}$.

Fig. 5. Transplantation of C2C12/VEGF cell sheets. Cell sheets were subcutaneously transplanted into the dorsal sites of nude mice. On $14 \mathrm{~d}$ after implantation, grafts were retrieved and analyzed by histological examination. a, b. Analysis of angiogenesis within implanted cell sheets. Representative images of section 
of Immunofluorescent staining for CD31 (a). The microvessel area in grafts was calculated as a percentage to the total area (b). Data are mean $\pm S D(n=5) .{ }^{*} P<0.05$ vs. C2C12/GFP cell sheet grafts. $c$, d. Angiogenic effect on tissue formation. Bright-field images of hematoxylin/eosin-stained cross-section of cell sheets (c). Cross-sectional area of cell sheet-derived tissues was measured (d). Data are mean $\pm \operatorname{SD}(n=5) .{ }^{*} P<0.05$ vs. C2C12/GFP cell sheet grafts. 
a

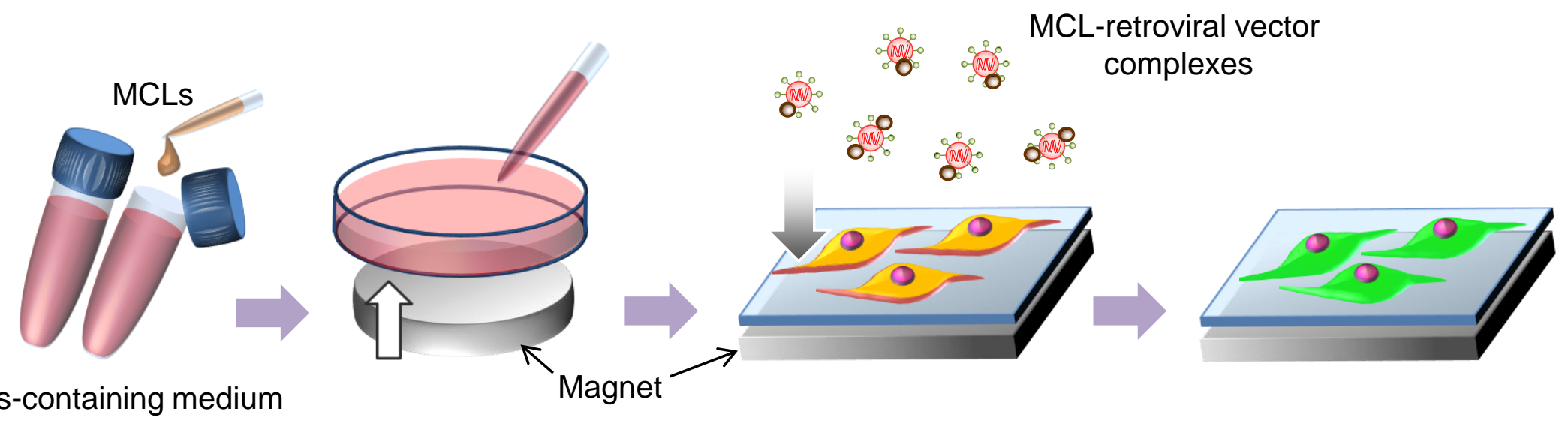

Virus-containing medium
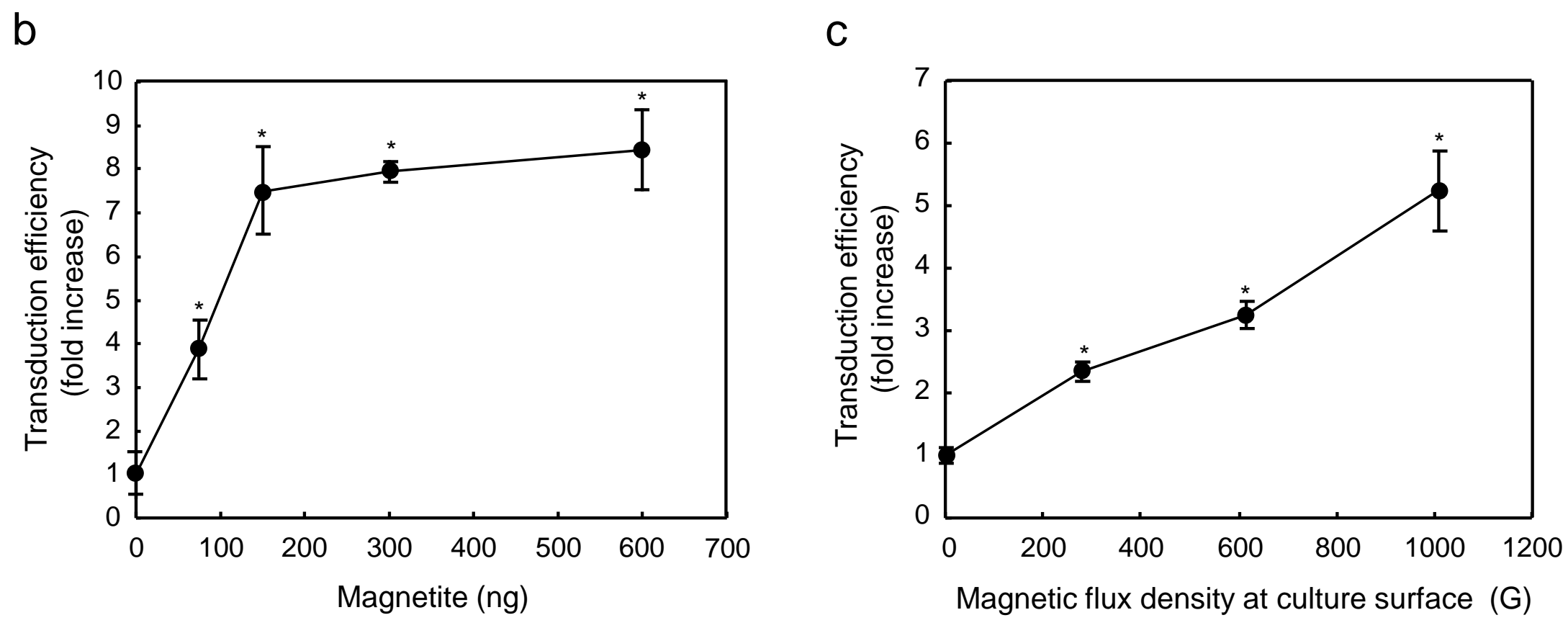

Figure 1. Akiyama et al. 
$a$
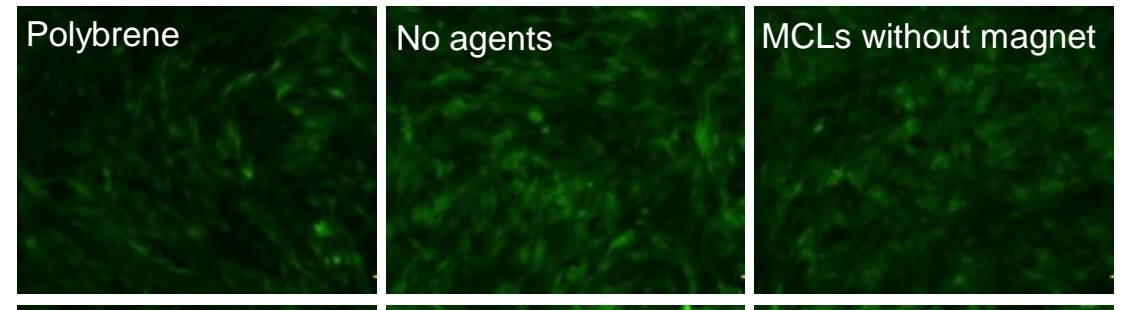

Polybrene + MCLs

without magnet

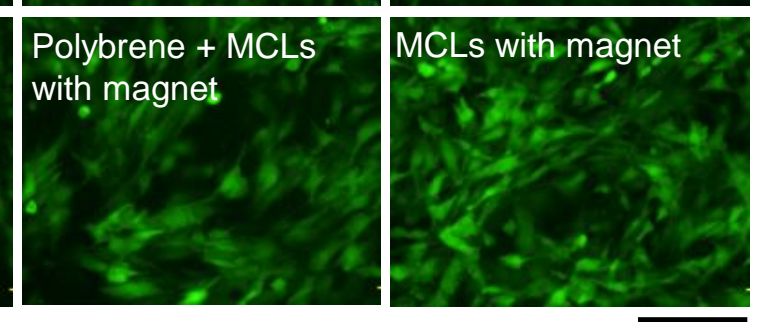

b

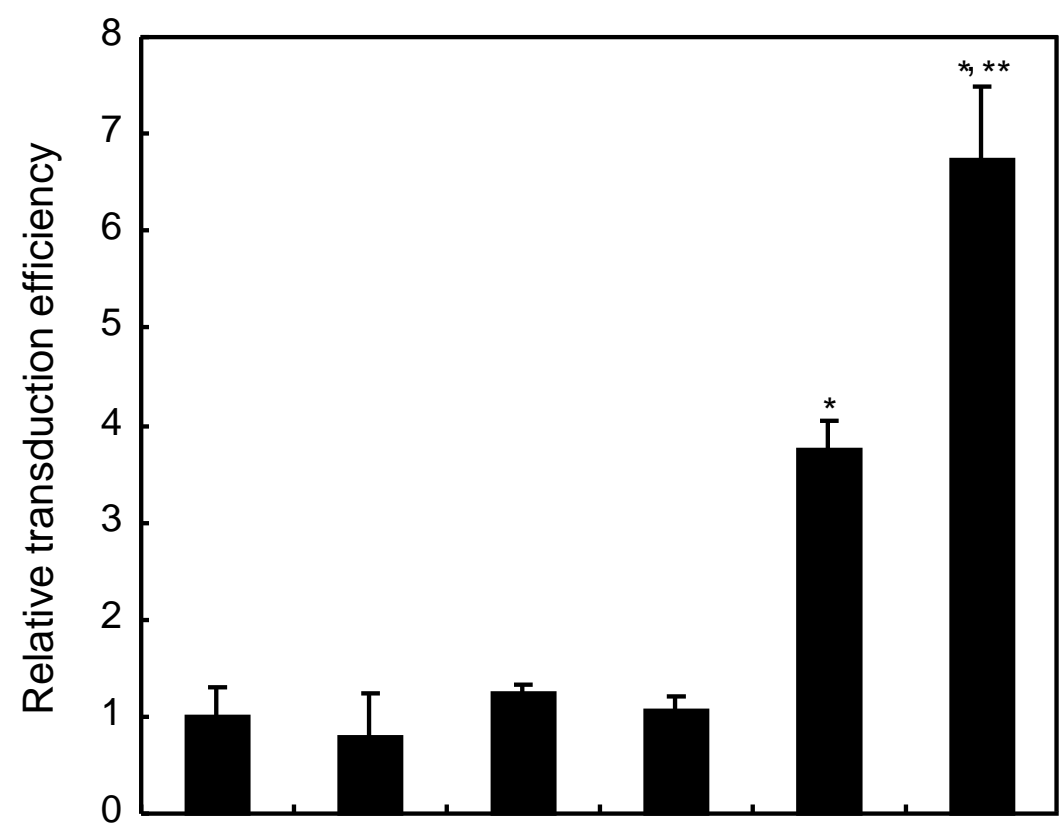

\begin{tabular}{|l|c|c|c|c|c|c|}
\hline Polybrene $(8 \mu \mathrm{g} / \mathrm{ml})$ & + & - & - & + & + & - \\
\hline MCLs $(600 \mathrm{ng})$ & - & - & + & + & + & + \\
\hline Magnet $(1010 \mathrm{G})$ & - & - & - & - & + & + \\
\hline
\end{tabular}

Figure 2. Akiyama et al. 

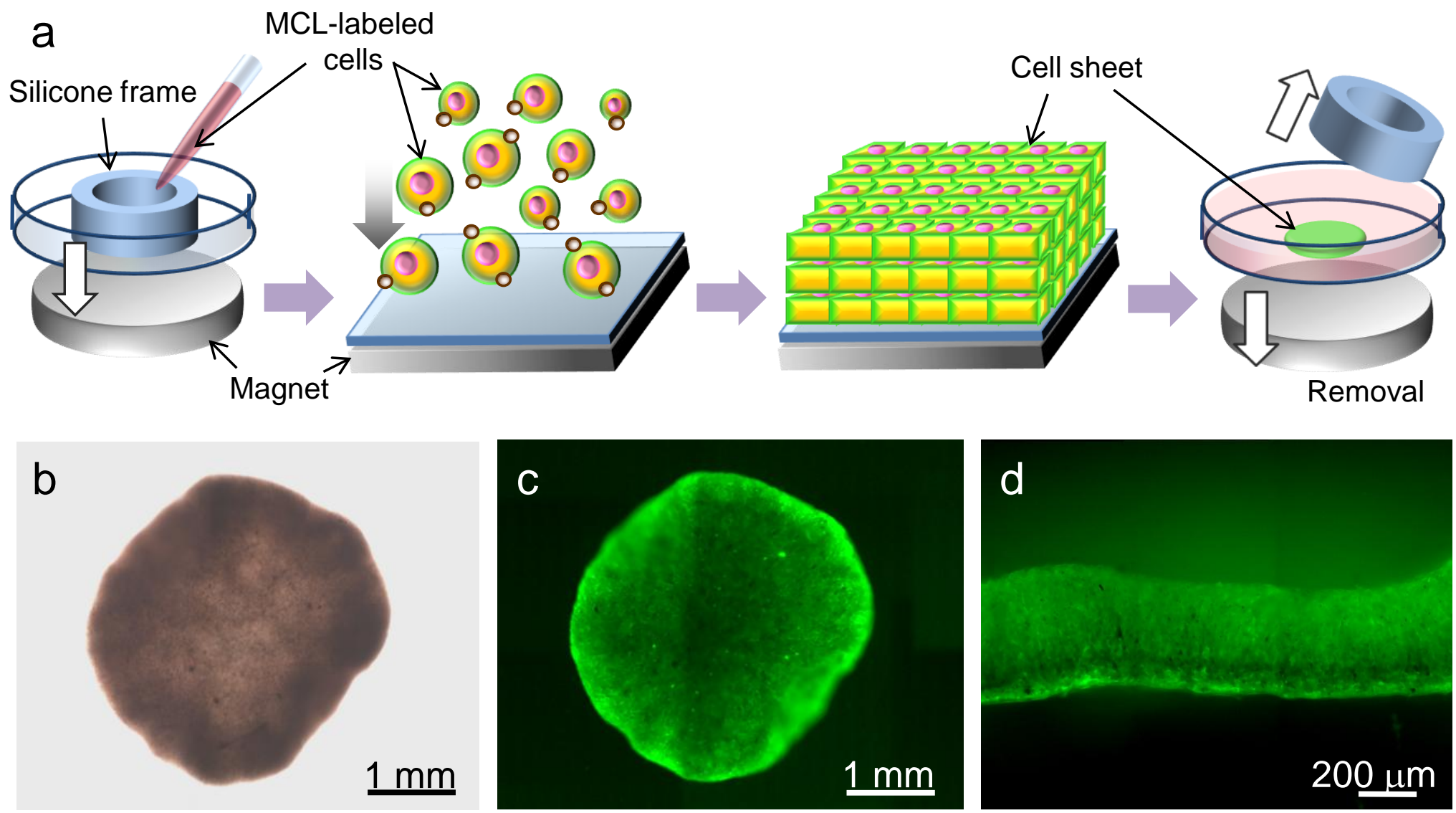

e

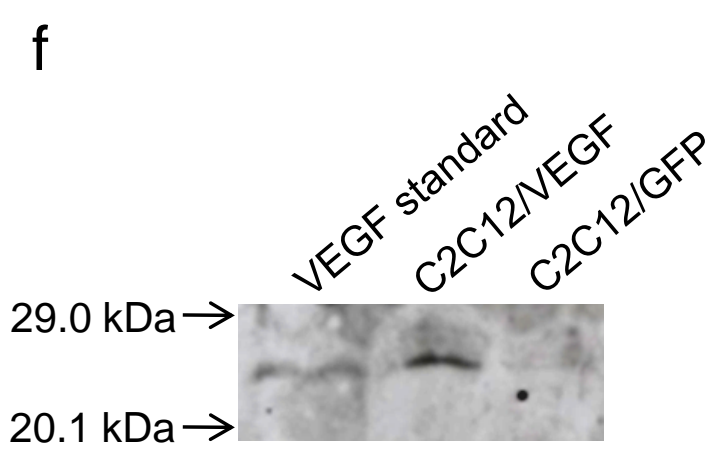

GAPDH

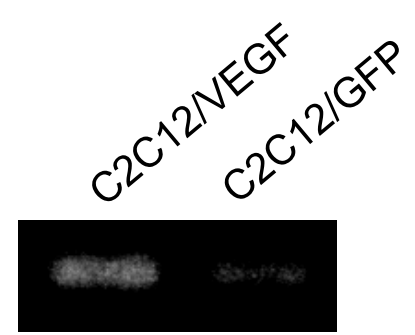

Comons

Figure 3. Akiyama et al. 

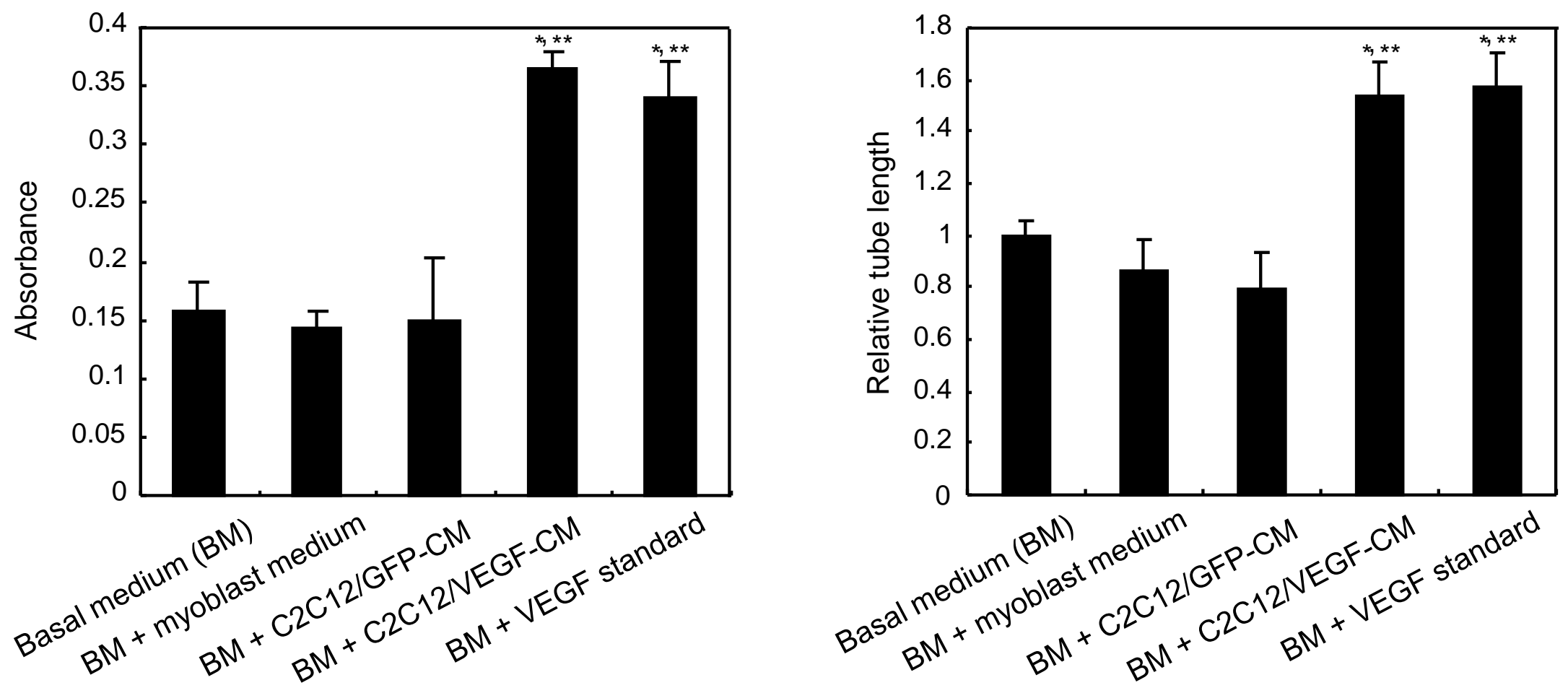

C
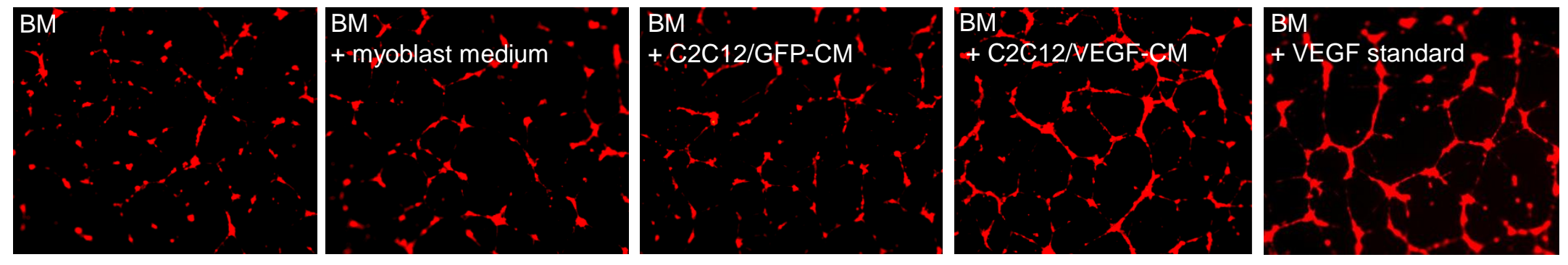

Figure 4. Akiyama et al. 
a

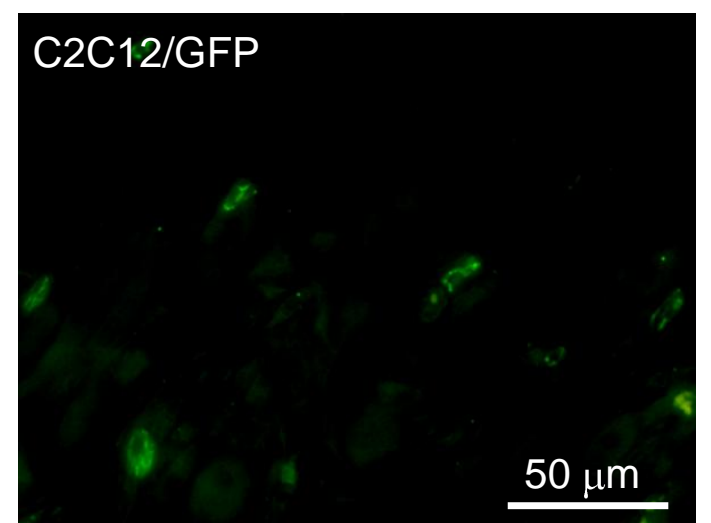

c

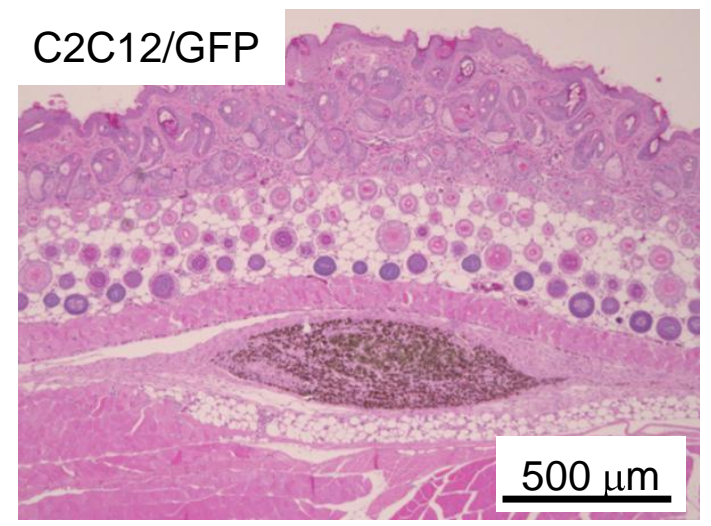

b
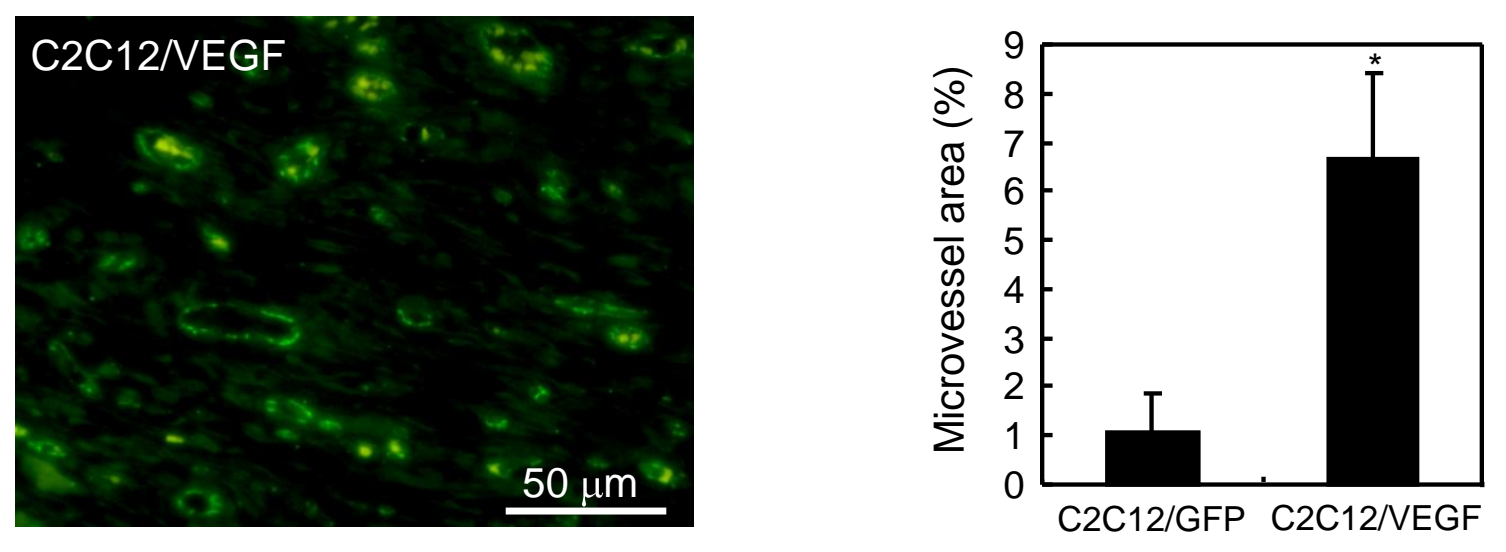

$d$

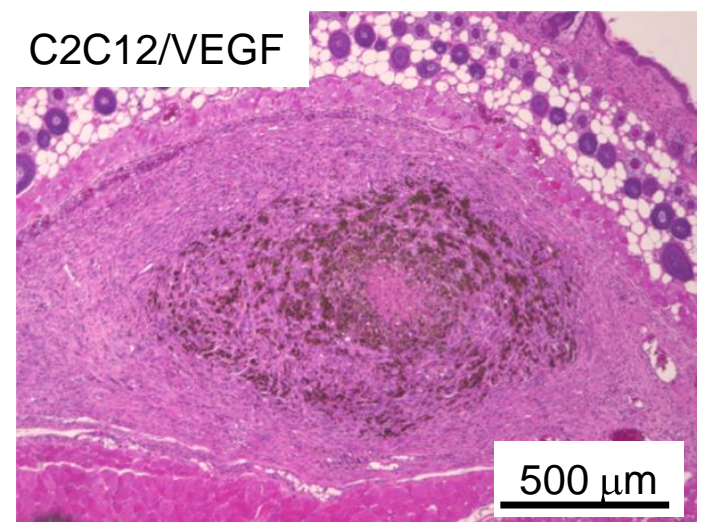

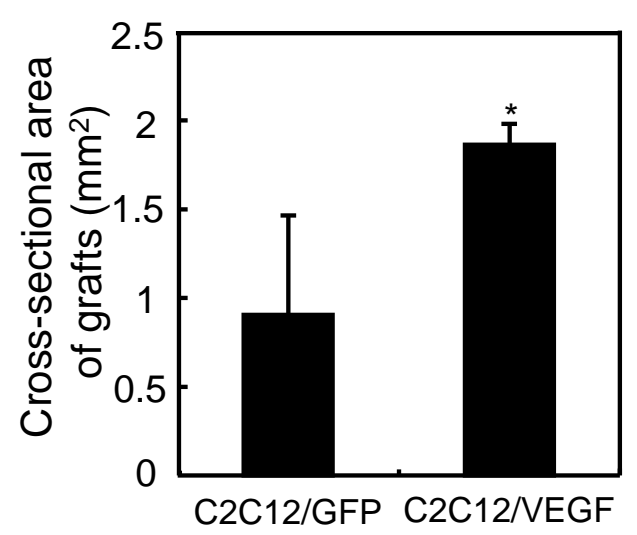

Figure 5. Akiyama et al. 